\title{
Yenidoğan Servis ve Yoğun Bakım Ünitesinde Tanı Alan Doğumsal Kalp Hastalığı Olgularının Geriye Dönük Değerlendirilmesi
}

\author{
Retrospective Evaluation of Congenital Heart Disease Cases \\ Diagnosed in Neonatal Service and Intensive Care Unit
}

\author{
Ayşe KARAPINARLI ${ }^{1}$, Ayşe Esin KIBAR GÜL ${ }^{2,4}$, Sevim ÜNAL ${ }^{3}$, Betül SiYAH BILGIN², Emine AZAK², \\ Vedat KAVURT2², Yasemin ÖZDEMIR ŞAHAN², Hazım Alper GÜRSU²,4,ibrahim Illker ÇETIN²,5
}

\author{
${ }^{1}$ Ankara Şehir Hastanesi, Çocuk Hastanesi, Çocuk Sağlığı ve Hastalıkları Kliniği, Ankara, Türkiye \\ ${ }^{2}$ Ankara Şehir Hastanesi, Çocuk Hastanesi, Çocuk Kardiyoloji Kliniği, Ankara, Türkiye \\ ${ }^{3}$ Ankara Şehir Hastanesi, Çocuk Hastanesi, Yenidoğan Kliniği, Ankara, Türkiye \\ ${ }^{4}$ Sağlık Bilimleri Üniversitesi, Çocuk Sağlığı ve Hastalıkları Anabilim Dalı, Çocuk Kardiyoloji Bilim Dalı, İstanbul, Türkiye \\ ${ }^{5}$ Yıldııım Beyazı Üniversitesi, Çocuk Sağlığı ve Hastalıkları Anabilim Dalı, Çocuk Kardiyoloji Bilim Dalı, Ankara, Türkiye
}

\section{Öz}

Amaç: Ekokardiyografi DKH'nin erken tanı ve izleminde önemli ve pratik bir tanı aracıdır. Çalsşmamızda yenidoğan kliniğinde DKH tanısı alan olguların sıkıı̆ı, tanılarının dağıımı ve risk faktörleri açısından değerlendirilmesi amaçlandı.

Gereç ve Yöntemler: Mayıs 2013-Mayıs 2017 tarihleri arasında YD servis ve yoğun bakımda takip edilen 2766 hasta geriye dönük incelendi. Kardiyoloji konsültasyonu istenen 762 term ve preterm YD'den DKH tanısı alan 365 bebek çalsşmaya dahil edildi. Patent foramen ovale (PFO) ve ilk 3 günde kapanan patent duktus arteriozus (PDA) olguları çallşmaya dahil edilmedi.

Bulgular: Merkezimizde DKH sıklğı \%13.2 olarak bulundu. Çoğunluğu term olan olguların \%60.5'i erkek, \%39.5'u kızdı. Hastaların en sık yatış nedeni solunumsal (\%28.3)'dü. Yüzde 19.9'unun ebeveynleri arasında akrabalık mevcuttu. En sık kardiyoloji konsültasyonu istenme nedeni üfürüm (\%27.4), solunum sıkıntısı (\%15.9) ve prematürite (\%10.1)'di. Hastaların \%96.2'sinde asiyanotik, \%3.8'inde siyanotik DKH vardı. Yenidoğanlarda en sık görülen asiyanotik DKH sırasılyla atriyal septal defekt (ASD) (\%40.8), pulmoner darlık (PD) (\%15.3), PDA (\%13.4), ventriküler septal defekt (VSD) (\%9.3) iken, siyanotik DKH sırasılyla hipoplastik sol kalp sendromu (HSKS) (\%1.1), pulmoner atrezi (PA) (\%0.8) ve çift çıkışlı sağ ventrikül (ÇÇSV) (\%0.8)'di. Hastaların \%7.1'inde DKH'ye eșlik eden genetik sendrom mevcut olup, bunların içinde \%38.5 ile Down Sendromu ilk sırada yer almaktaydı. Hastaların \%10.1'inde major ekstrakardiyak anomali saptanmıştır. Diyabetik anne bebeklerinin \%20.6'sında septal hipertrofi görüldü. Çalışmamızda tek zamanlı nabız oksimetre ölçümleri yapılmış olup siyanotik DKH grubunun \%72.7'sinde SatO2'nin <\%90; asiyanotik DKH grubunun \%76.3'ünde SatO2'nin $\geq \% 95$ olduğu ve anlamlı olarak farkı görüldü $(p<0.05)$. Asiyanotik DKH'ye eşlik eden hipokseminin çoğunlukla solunumsal hastallklara (\%66.7) bağı olduğu saptandı. Hastaların 21'i (\%5.8) ileri tetkik ve tedavi amaçlı başka merkezlere sevk edilirken, 25'i (\%6.8) de çoğunlukla sepsis nedeniyle kaybedildi.

(1D)

KARAPINARLI A

KIBAR GÜL AE

ÜNALS

SIYYAH BILGIN B

AZAKE
KAVURT V

ÖZDEMIR ȘAHANY

GÜRSU AH

ÇETIN II
:0000-0001-7800-0180 $: 0000-0001-7833-7701$ :0000-0002-7863-1924 :0000-0003-3807-4809 :0000-0002-7841-1331 $.0000-0002-9756-4616$ $.0000-0002-9756-4616$ .0000-0003-4279-953 :0000-0002-0707-2678

\begin{abstract}
Çıkar Çatışması / Conflict of Interest: Tüm yazarlar adına, ilgili yazar çıkar çatıșması olmadığını belirtir.
Etik Kurul Onayı / Ethics Committee Approval: Çalıșma için, Ankara Çocuk Sağlığı ve Hastalıkları Hematoloji Onkoloji Eğitim ve Araştırma Hastanesi Klinik Araştırmalar Etik Kurulu'dan onay alındı (03.07.2017-2017-071).

Yazarların katkısı / Contribution of the Authors: KARAPINARLI A: Araştırma ve/veya makalenin hipotezini veya fikrini oluşturan, Sonuçlara ulaşmak için planlama/metodoloji belirleme, Araştırma/çalışmanın sorumluluğunu üstlenmek, ilerlemenin seyrini denetlemek, Hasta takibinde sorumluluk almak, ilgili biyolojik malzemelerin toplanması, veri yönetimi ve raporlama, deneylerin yürütülmesi, Sonuçların mantıksal olarak Yorumlanması ve sonuçlandırıması, Çalıșma için gerekli literatür taramasında sorumluluk almak, Çalısmanın bütününün veya önemli bölümlerinin yazımında sorumluluk almak. KiBAR GÜL AE: Araştırma ve/veya makalenin hipotezini veya fikrini oluşturan, Sonuçlara ulaşmak için planlama/ metodoloji belirleme, Araștırma/çalıșmanın sorumluluğunu üstlenmek, ilerlemenin seyrini denetlemek. ÜNAL S: Araştırma ve/veya makalenin hipotezini veya fikrini olușturan. SiYAH BiLGiN B: Sonuçlara ulașmak için planlama/metodoloji belirleme. AZAK E: Hasta takibinde sorumluluk almak, ilgili biyolojik malzemelerin toplanması, veri yönetimi ve raporlama, deneylerin yürütülmesi, Sonuçların mantıksal olarak Yorumlanması

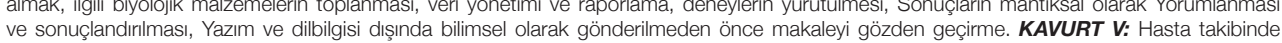
sorumluluk almak, ilgili biyolojik malzemelerin toplanması, veri yönetimi ve raporlama, deneylerin yürütülmesi, Çalışmanın bütününün veya öneml bölümlerinin yazımında sorumluluk almak. ÖZDEMIR ŞAHAN Y: Sonuçların mantıksal olarak Yorumlanması ve sonuçlandırıması. GÜRSU $\boldsymbol{A H}$ : Yazım ve dilbilgisi dıșında bilimsel olarak gönderilmeden önce makaleyi gözden geçirme. ÇETiN ii: Araștırma/çalıșmanın sorumluluğunu üstlenmek, ilerlemenin seyrini denetlemek, Yazım ve dilbilgisi dışında bilimsel olarak gönderilmeden önce makaleyi gözden geçirme.

Atıf yazım şekli / How to cite : Karapınarı A, Kibar Gül AE, Ünal S, Siyah Bilgin B, Azak E, Kavurt V ve ark. Yenidoğan Servis ve Yoğun Bakım Ünitesinde Tanı Alan Doğumsal Kalp Hastalığı Olgularının Geriye Dönük Değerlendirilmesi. Türkiye Çocuk Hast Derg 2022;16:191-199.
\end{abstract}

Geliş tarihi/ Received : 29.03 .2021 Kabul tarihi / Accepted : 28.05.2021 Elektronik yayın tarihi : 27.09 .2021 Online published

DOI: 10.12956/tchd.902641 
Sonuç: Yenidoğan yoğun bakımda yatan bebeklerde ekokardiyografi önemli bir tanı aracı olarak gözükmektedir. Doğumsal kalp hastalıklarının erken saptanması girişimsel işlemlerin erken yapılmasına ve böylece mortalite ve morbiditenin azalmasında fayda sağlayacaktır.

Anahtar Sözcükler: Doğumsal kalp hastalığı, Ekokardiyografi, Yenidoğan yoğun bakım

\section{ABSTRACT}

Objective: Echocardiography is an important and pratical diagnostic tool for early diagnosis and follow-up of CHD. In our study, we aimed to evaluate the frequency, distribution of diagnoses and risk factors of cases diagnosed with $\mathrm{CHD}$ in the neonatal intensive care units (NICU) and neonatal services.

Material and Methods: 2766 patients who were followed in NICU and neonatal services between May 2013 and May 2017 were retrospectively analyzed. 365 newborn diagnosed with CHD of 762 babies were requested pediatric cardiology consultation were included in the study. Cases diagnosed with patent foramen ovale and patent ductus arteriosus (PDA) that closed in first 3 days were excluded from study.

Results: The frequency of CHD in our center was 13.2\%. Most of the cases were term births, $60.5 \%$ of them were male and $30.9 \%$ were female. The most common reasons for hospitalization were respiratory diseases (28.3\%). There was kinship between the parents of 19.9\%. The most common reasons for cardiology consultation were murmur (27.4\%), respiratory distress (15.9\%) and prematurity (10.1\%). Ninety six point two percent of the patients had acyanotic CHD, and 3.8\% had cyanotic CHD. The most common acyanotic $\mathrm{CHD}$, in order of frequency, were atrial septal defect (ASD) (40.8\%), pulmonary stenosis (PS) (15.3\%), PDA (13.4\%), ventricular septal defect (VSD) (9.3\%). The most common cyanotic CHD, in order of frequency, were hypoplastic left heart syndrome (1.1\%), pulmonary atresia $(0.8 \%)$ and double outlet right ventricle $(0.8 \%)$. Seven point one percent of the patients had a genetic syndrome accompanying $\mathrm{CHD}$, and Down syndrome was in the first place with 38.5\%. Major extracardiac anomaly was found in 10.1\% of the patients. While $9.3 \%$ were followed up as diabetic mothers' babies, $20.6 \%$ of them had septal hypertrophy. One-time pulse oximetry measurements were made in our study. In $72.7 \%$ of the cyanotic CHD group SatO2 was less than $90 \%$, whereas in $76.3 \%$ of the acyanotic $\mathrm{CHH}$ group, SatO2 was $95 \%$ and above, and it was found to be significantly different $(\mathrm{p}<0.05)$. It was observed that the hypoxemia accompanying acyanotic CHD was mostly due to respiratory diseases (66.7\%). While 21 patient (5.8\%) were referred to other centers for further examination and treatment, 25 patient (6.8\%) were mostly lost due to sepsis.

Conclusion: Echocardiography seems to be an important diagnostic tool in newborns hospitalized in the NICU. Early detection of CHD will be beneficial in applying interventional procedures early and in reducing mortality and morbidity.

Key Words: Congenital Heart Disease, Echocardiography, Neonatal intensive care unit

\section{GiRiş}

Doğumsal kalp hastalıkları (DKH), anne karnında kalbin normal gelişimi sonucunda açı̆̆a çıkan yapısal veya fonksiyonel kalp anomalilerini içeren hastalıklardır. Yenidoğan dönemindeki (YD) en sık görülen doğumsal anamolidir ve canlı doğumların \%0.8'inde görülür (1). Tüm majör doğumsal anomalilerin \%28'inden sorumludur (2). Çoğu DKH vakasında etyoloji bilinmemekte birlikte genetik ve çevresel nedenlere bağlı multifaktöriyel olduğu düşünülmektedir (3).

Yenidoğan döneminde DKH tanısının konması yaşamın diğer dönemlerine göre daha güçtür. Klinikte solunum sıkıntısı, siyanoz, şok gibi ağır belirtiler olabileceği gibi, asemptomatik üfürüm de olabilir (4). Yenidoğanlarda DKH saptamada ekokardiyografi (EKO) fizik muayeneye göre 4-10 kat daha duyarlı olabildiği bildirilmektedir (5).

Tüm tanı ve tedavilerde ilerlemeye rağmen doğumsal malformasyonlar içinde DKH en sık YD ölüm nedenidir (\%7) $(6,7)$. Yenidoğanlarda mortalite, morbidite oranlarının ve harcanan sağlık masraflarının azaltıması için erken tanı ve tedavi büyük önem taşımaktadır.

Çalışmamızda hastanemiz yenidoğan kliniğinde yatan bebekler arasında kardiyoloji konsültasyonu istenen ve DKH tanısı olan vakaların demografik, klinik ve ekokardiyografi bulguları karşılaştırılmış, yenidoğan bebeklerde DKH için bazı risk faktörleri ve mortalite oranlarının değerlendirilmesi amaçlanmıştır. Elde edilen sonuçlarla uygulanan sağlık hizmetinin ve programlarının etkinliğini arttırmaya yönelik çalışmalar yapılmasına yardımcı olunması planlanmaktadır.

\section{GEREÇ ve YÖNTEMLER}

Çalışmamızda Mayıs 2013-Mayıs 2017 tarihleri arasında hastanemiz yenidoğan servis ve yoğun bakım ünitesinde yatan 2766 bebek arasından pediatrik kardiyolog tarafından kardiyak değerlendirilmesi ve ekokardiyografisi yapılmış ve bunun sonucunda DKH tanısı alan 365 bebek geriye dönük olarak değerlendirildi.

Hastaların dosyaları incelenerek sosyodemografik verileri, doğum bilgileri, maternal ve gebelik özellikleri, yatış nedenleri, yatış anı şikayetleri, fizik muayene bulguları ve oksijen saturasyon değerleri, telekardiyografi (TELE) bulguları, kardiyoloji konsültasyon nedeni, EKO tanıları, EKO'nun kaçıncı gün yapıldığı, eşlik eden genetik/metabolik hastalıklar, ekstrakardiyak anomali varlığı, aldığı tedaviler, yatış süresi, taburculuk, sevk edilme, eksitus durumu ve nedeni çalışma formuna kaydedildi.

Patent foramen ovale tanısı alan olgular, ilk 3 günde kapanan ve suprasternal çalışmada kapanmakta olan ince PDA olguları normal kalp bulguları kabul edilerek çalışmaya dahil edilmedi. 
Yenidoğan kliniğimizde yatan bebekler önce yenidoğan uzmanı tarafından değerlendirildikten sonra kardiyoloji konsültasyonu istendi. Pediatrik kardiyoloji uzmanı tarafindan yapılan kardiyovasküler sistem muayenesi, elektrokardiyografi ve EKO ile değerlendirilme sonucu DKH tanısı konuldu. Ekokardiyografik değerlendirme Vivid 7 Pro (General Electric, Horten, Norway) cihazı ve $7 \mathrm{MHz}$ multifrekans transducer ile Philips IE 33 (The Netherlands) X5-1 prob kullanılarak yapıldı.

Çalışma için Ankara Çocuk Sağlığı ve Hastalıkları Hematoloji Onkoloji Eğitim ve Araştırma Hastanesi Klinik Araștırmalar Etik Kurulu'dan onay alındı (03.07.2017-2017-071).

\section{İstatistiksel analiz}

Çalışma kapsamında toplanılan verilerin analizinde, Statistical Package for Social Sciences (SPSS), Windows için sürüm 22.0 (SPSS Inc., Chicago, USA) bilgisayar paket programı kullanıldı. Verilerin tanımlayıcı özellikleri ortalama \pm standart sapma, ortanca (minimum-maksimum), sayı ve yüzde olarak ifade edildi. Normal dağılıma uymadığı saptanan değişkenler için iki bağımsız grup arasındaki istatistiksel anlamllıklarda Mann-Whitney $U$ Testi kullanıldı. Kategorik değişkenlerin değerlendirilmesinde Pearson Ki-kare testi ve Fisher' Exact Test kullanıldı. İstatistik anlamılıı düzeyi $p<0.05$ olarak kabul edildi.

\section{BULGULAR}

Hastanemiz yenidoğan servisinde yaklaşık 4 yıllık dönemde yatan 2766 hastadan 762'sinden (\%27.5) pediatrik kardiyoloji konsültasyonu istendi ve bu olguların 365'inde DKH saptandı. Doğumsal kalp hastalığının yatırılan tüm hastalarda bulunma oranı \%13.2 saptanırken; konsültasyon istenen hastalarda bu oran \%47.9 olarak bulundu.

Çalışma grubunu oluşturan 365 bebeğin \%60.5 ( $n=221$ )'i erkek olup \%39.5 ( $n=114)^{\prime}$ 'i kızdı. Hastaların \%60.3'ü $(n=220)$ term, \%39.2'si ( $n=143)$ preterm ve \%0.5'i $(n=2)$ postterm doğumdu. Hastaların anne yaşı ortalaması $28 \pm 5.85$ yıldı. Doğum haftası ortalaması $36.4 \pm 3.62$ hafta, ortalama doğum ağıllığı $2696 \pm 826$ gr, yatış yașı ortalaması $11.58 \pm 16.88$ gün, tanı alma yaşı 13.6 \pm 16.51 gün, ortalama $E K O$ yapılma süresi $2.78 \pm 3.78$ gündü. Hastaların ortalama yatış süresi $15.4 \pm 14.6$ gündü (Tablo I).
Yatış tanıları gruplandırılığında en sık yatış nedeni solunumsal nedenler ( $n=103, \% 28.3)$, enfeksiyöz nedenler ( $n=41, \% 11.2)$ ve sarlık ( $n=32, \% 8.8$ )'di. Hastaların \%6.8'i kardiyak; \%93.2'si non-kardiyak nedenlerle yatmıştı. Yatış süreleri incelendiğinde ortalama en uzun süreli yatış sebebinin prematürite $(28.4 \pm 21.3$ gün), gastrointestinal sistem (GiS) hastalıkları $(21,46 \pm 17.62$ gün) nedenli olduğu görüldü. Kardiyak nedenler ile yatış süresi (10.5 \pm 16.1 gün) 5.sırada yer almaktaydı (Tablo II).

Çalışmaya dahil edilen 365 olguda en sık başvuru şikâyeti \%34.5 ( $n=126)$ ile solunum sıkıntısı, \%10.9 $(n=40)$ ile sarlik, \%8.7 ( $n=32)$ ile emmede azalma ve \%7.3 $(n=27)$ ile atești. Fizik muayene bulgusu olarak sıklik sırasına göre \%34.5 ( $n=126)$ 'inde üfürüm, \%27.7 ( $n=101)$ 'sinde takipne ve \%23 ( $n=84)$ 'ünde retraksiyon görüldü (Tablo III).

Vakaların 100'üne (\%27.4) üfürüm duyulması, 58'ine (\%15.9) solunum sıkıntısı, 37'sine (\%10.1) prematürite, 36'sına (\%9.9) metabolik hastalık, 27'sine (\%7.4) kardiyak anomali taraması, 24'üne (\%6.6) dismorfik fenotip, 24'üne (\%6.6) siyanoz, 18'ine (\%4.9) operasyon öncesi değerlendirme ve 16'sına (\%4.4) aritmi nedeniyle kardiyolojik değerlendirme ve EKO yapıldı (Tablo IV). Ekokardiyografisi yapılan 365 yenidoğanın 351 (\%96.2)'inde asiyanotik DKH, 14 (\%3.8)'ünde siyanotik DKH saptandı. İzole majör bozukluğa göre 149'unda (\%40.8) atrial septal deft (ASD), 56'sında (\%15.3) pulmoner darlık (PD), 49'unda (\%13.4) patent duktus arteriosus (PDA), 34'ünde (\%9.3) ventriküler septal defekt (VSD), 6'sında (\%1.6) aort koarktasyonu (AK), 4'ünde (\%1.1) hipoplastik sol kalp sendromu (HSKS), 3'ünde $(\% 0.8)$ pulmoner atrezi (PA), 3'ünde (\%0.8) çift çıkışlı sağ ventrikül (ÇÇSV), 1'inde (\%0.3) fallot tetrolojisi (FT), 1'inde (\%0.3) trikuspid atrezisi (TA), 1 'inde (\%0.3) tek ventrikül ve 1 'inde (\%0.3) total anormal pulmoner venöz dönüş anomalisi (TAPVDA) görüldü (Tablo V). Sadece EKO bulgularına bakılarak VSD görülme oranı \%19.2 ( $n=70)$ saptandı.

Asiyanotik ve siyanotik olmak üzere doğumsal kalp hastalığı grupları arasında doğum ağılığı ve doğum haftası açısından anlamlı fark görülmedi ( $p>0.05$ ). Asiyanotik $\mathrm{DKH}$ olgularının

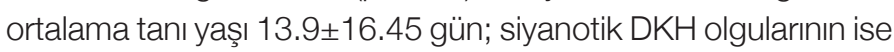
$5.86 \pm 4.8$ gün saptandı. Asiyanotik DKH hastalarında ortalama yatış süresi $15.59 \pm 14.31$ gün, siyanotik $\mathrm{DKH}$ hastalarında ise $11.5 \pm 21.01$ gündü. Yatış süresi asiyanotik $\mathrm{DKH}$ grubunda

Tablo I: Olguların demografik özellikleri.

\begin{tabular}{|l|c|c|c|}
\hline \multicolumn{1}{|c|}{$\mathbf{n = 3 6 5}$} & Ortalama \pm SD & Min-Maks & Median \\
\hline Anne yaşı (yıl) & $28 \pm 5.85$ & $15-46$ & 27 \\
\hline Doğum haftası & $36.4 \pm 3.62$ & $23-42$ & 38 \\
\hline Doğum ağırlı̆ı (gr) & $2696 \pm 826$ & $575-3795$ & 2800 \\
\hline Yatış yaşı (gün) & $11.58 \pm 16.88$ & $0-133$ & 5 \\
\hline Tanı yaşı (gün) & $13.6 \pm 16.51$ & $0-93$ & 7 \\
\hline Yatış sonrası EKO yapılma süresi (gün) & $2.78 \pm 3.78$ & $0-26$ & 1 \\
\hline Yatış süresi (gün) & $15.4 \pm 14.6$ & $0-89$ & 12 \\
\hline
\end{tabular}

SD: Standart sapma, EKO: Ekokardiyografi, gr: gram. 
Tablo II: Olguların Yatıș Nedenlerinin Gruplandırılması ve ortalama Yatış Süreleri.

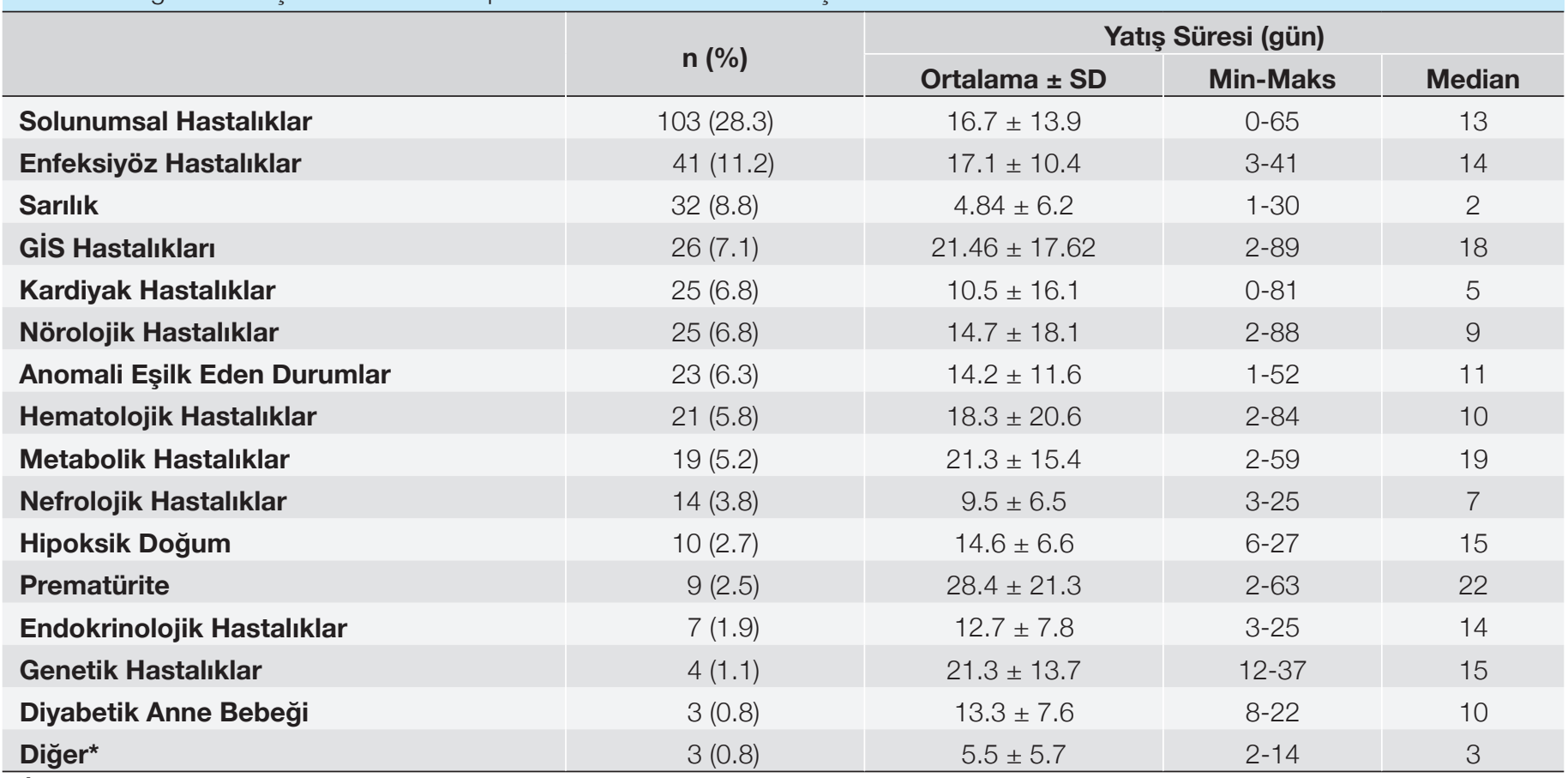

Gis: Gastrointestinal sistem. *uyuşturucu madde kullanan anne bebeği 2 adet, gelişimsel kalça displazisi 1 adet

Tablo III: Olguların Yatış Anı Fizik Muayene Bulgularının Değerlendirilmesi*.

\begin{tabular}{|l|c|}
\hline \multicolumn{1}{|c}{ Fizik Muayene Bulgusu (n=365) } & $\mathbf{n}(\mathbf{\%})$ \\
\hline Üfürüm & $126(34.5)$ \\
\hline Takipne & $101(27.7)$ \\
\hline Retraksiyon & $84(23.0)$ \\
\hline Sarılık & $61(16.7)$ \\
\hline Dismorfik görünüm & $34(9.3)$ \\
\hline Raller & $27(7.4)$ \\
\hline Hipotoni & $25(6.8)$ \\
\hline İnleme & $23(6.3)$ \\
\hline Siyanoz & $19(5.2)$ \\
\hline Batında distansiyon & $19(5.2)$ \\
\hline Belirgin FMB yok & $36(9.9)$ \\
\hline
\end{tabular}

*Yatış anında birden fazla fizik muayene bulgusu olabilir. FMB: Fizik muayene bulgusu

siyanotik DKH grubuna göre anlamlı olarak daha yüksek saptandı (p:0.008).

Annelerin 76 (\%20.8)'sında ilaç kullanımı, 65 (\%17.8)'inde geçirilmiş enfeksiyon, 23 (\%6.3)'ünde vajinal kanama, 34 (\%9.3)'ünde diyabet (en sık), 25 (\%6.8)'inde hipertansiyon ve 33 (\%9.0)'ünde sigara kullanımı mevcuttu. Annelerin 348 (\%95.3) tanesinde en az 1 doktor izlemi mevcut olup 343 (\%94.0) tanesinde prenatal ultrasonografi yapılmıştı. Bu hastaların 57 (\%15.6)'sinde anomali mevcut olup 8 (\%2.2) tanesinde kardiyak patoloji mevcuttu. Annelerin önceki gebeliklerinde 73 (\%20 .0)'ünde abort ve 13 (\%3.6)'ünde intrauterin eksitus öyküsü bulunmaktaydı.
Tablo IV: Pediatrik Kardiyoloji Konsültasyon Nedenleri*.

\begin{tabular}{|l|r|}
\hline \multicolumn{1}{|c}{ Konsültasyon sebebi } & $\mathbf{n}(\%)$ \\
\hline Üfürüm & $100(27.4)$ \\
\hline Solunum sıkıntısı & $58(15.9)$ \\
\hline Prematürite & $37(10.1)$ \\
\hline Metabolik hastalık & $36(9.9)$ \\
\hline Kardiyak anomali taraması & $27(7.4)$ \\
\hline Dismorfik fenotip & $24(6.6)$ \\
\hline Siyanoz & $24(6.6)$ \\
\hline Operasyon öncesi değerlendirme & $18(4.9)$ \\
\hline Aritmi & $16(4.4)$ \\
\hline Sepsis & $15(4.1)$ \\
\hline Hipoksik doğum & $12(3.3)$ \\
\hline Diyabetik anne bebeği & $11(3.0)$ \\
\hline Pnömoni & $9(2.5)$ \\
\hline Emerken morarma & $8(2.2)$ \\
\hline Apne & $5(1.4)$ \\
\hline Konjenital anomali & $5(1.4)$ \\
\hline Mekonyum aspirasyon sendromu & $4(1.1)$ \\
\hline Femoral nabız alınamaması & $3(0.8)$ \\
\hline Hipotoni & $3(0.8)$ \\
\hline Diğer & $11(3.0)$ \\
\hline$H$
\end{tabular}

*Hastaların birden fazla konsültasyon sebebi olabilir.

Hastaların 34 (\%9.3) tanesi (DAB) olarak takip edildi. Bunların 23 tanesi (\%67.6) erkek, 11 tanesi (\%32.4) kıdı. Bu bebeklerin tamamında asiyanotik DKH hastalığı görülmüş olup sıklık 
Tablo V: Doğumsal Kalp Hastalıklı Olguların Dağılımı

\begin{tabular}{lr}
\hline \multicolumn{1}{c}{ Doğumsal Kalp Hastalığı } & $\mathbf{n}(\%)$ \\
\hline Asiyanotik Doğumsal Kalp Hastalığı & $351(96.2)$ \\
Atriyal Septal Defekt & $149(40.8)$ \\
Pulmoner Darlık & $56(15.3)$ \\
Patent Duktus Arteriozus & $49(13.4)$ \\
Ventriküler Septal Defekt & $34(9.3)$ \\
ASD + PDA & $34(9.3)$ \\
ASD + VSD & $17(4.7)$ \\
Aort Koarktasyonu & $6(1.6)$ \\
VSD + PDA & $6(1.6)$ \\
Siyanotik Doğumsal Kalp Hastalığı & $14(3.8)$ \\
Hipoplastik Sol Kalp Sendromu & $4(1.1)$ \\
Pulmoner Atrezi & $3(0.8)$ \\
Çift Çıkıșı Sağ Ventrikül & $3(0.8)$ \\
Fallot Tetralojisi & $1(0.3)$ \\
Triküspit Atrezisi & $1(0.3)$ \\
Tek Ventrikül & $1(0.3)$ \\
Total Anormal Pulmoner Venöz Dönüş & $1(0.3)$ \\
Anomalisi & $365(100)$ \\
\hline Toplam &
\end{tabular}

ASD: Atriyal septal defekt, PDA: Patent duktus arteriozus, VSD: Ventriküler septal defekt

sırasına göre ASD ( $n=11, \% 32.4)$, VSD ( $n=8, \% 23.5), P D(n=6$, $\% 17.6), \operatorname{PDA}(n=4, \% 11.8), A S D+V S D(n=3, \% 8.8), A S D+P D A$ $(n=1, \% 2.9)$ ve $A K(n=1, \% 2.9)$ yer almaktaydı. Vakaların 7 (\%20 ,6)'sinde septal hipertrofi görüldü. Diyabetik anne bebeklerinde yatışların en sık solunumsal hastalıklar ( $n=11, \% 32.4)$, metabolik hastalıklar ( $n=7, \% 20.6)$, nörolojik hastalıklar ( $n=3, \% 8.8)$ ve gastrointestinal hastalıklar $(n=3, \% 8.8)$ nedeni ile olduğu görüldü.

Hasta ebeveynleri arasında akrabalık durumu bilinen 352 hastanın \%19.9 (n=70)'unda akrabalık evliliği mevcuttu. Bunlardan 49'u (\%70.0) 2. derece akrabaydı. Çalışma grubundaki 26 hastada (\%7.1) eşlik eden genetik sendromu mevcuttu. Bu hastaların 11'i (\%42.3) erkek 15 (\%57.7) tanesi kı olup vakaların 10 tanesi (\%38.5)'i Down Sendromu, 2 (\%7.7) tanesi Edward Sendromu'ydu (Tablo VI). Hastaların 37 (\%10.1) tanesinde 1 veya daha fazla majör ekstrakardiyak anomali saptandı. Toplamda 58 adet majör anomali görülmüştür. Bunlar içinde birinci sırada gastrointestinal sistem (GiS) ( \%25.9) anomalileri oluşturmaktaydı (Tablo VII). Elektronik ortamda 283 hastanın TELE'sine ulaşılabildi. Bunların 270 tanesi asiyanotik DKH iken 246 (\%91.1) tanesinde kardiyo torasik oran (KTO) normaldi. Kalan 13 tanesi siyanotik DKH'di ve 8 (\%61.5) tanesinin KTO'su artmıştı ( $\mathrm{p}<0.0001)$.

Asiyanotik DKH hastalarının 296'sında (\%84.3) takibinde siyanoz görülmezken, siyanotik DKH hastalarının 8 (\%57.1)'inde siyanoz görüldü ve anlamlı fark bulundu (p:0.001). Tüm hastaların SatO2 ölçüm ortalaması \%94.65 bulundu. Asiyanotik DKH hastalarında SatO2 ölçüm ortalaması

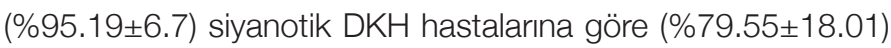
anlamlı yüksekti (p:0.001). Siyanotik DKH olan grupta hastaların çoğunlukla oksijen saturasyonları \%90'ın altında iken asiyanotik DKH olan hastaların çoğunlukla \%95 ve üstündeydi. Asiyanotik DKH grubunda 36 hastanın oksijen saturayonu \%90'ın altında ölçüldü. Bu vakaların en sık yatış sebebinin \%66.7 ( $n=24)$ ile solunumsal hastalıklar, \%8.3 $(n=3)$ kardiyak hastalıklar, \%8.3 ( $n=3$ ) enfeksiyöz hastalıklar olduğu görüldü. Asiyanotik DKH hastalarında SatO2 değerinin \%90'ın altında olması ile solunumsal hastalıklarla yatması arasındaki ilişki istatistiksel olarak anlamlı saptandı ( $\mathrm{p}<0.0001)$.

Doğumsal kalp hastalığı saptanan 365 hastanın 319'u (\%87.4) hasta taburcu olurken 21 tanesi (\%5.8) dış merkeze acil cerrahi girişim gerekmesi ve hastanemizde bu işlemlerin yapılamaması nedeniyle sevk edildi. Sevk edilen 21 hastanın 5'i (\%23.8) ASD (eşlik eden kalp dışı anomiler), 1'i (\%4.8) PDA (medikal tedaviye yanıt vermeyen hemodinamik anlamlı), 3'ü (\%14.3) ASD+PDA, 4'ü (\%19.0) AK, 3'ü (\%14.3) HSKS, 2'si (\%9.5) ÇÇSV, 1'i (\%4.8) FT, 1'i (\%4.8) TAPVDA, 1'i (\%4.8) tek ventriküldü. 25 $(\% 6,8)$ hasta eksitus oldu. Eksitus sebepleri sepsis $(n=18$, $\% 72)$, kardiyak nedenler ( $n=5, \% 20)$, dissemine intravasküler koagülasyon ( $n=1, \% 4)$ ve metabolik kriz ( $n=1, \% 4)^{\prime}$ di. Kardiyak nedenler içinde sırasıyla septik miyokardit, aritmi, pulmoner hipertansiyon ve kardiyojenik şoka bağlı kalp yetmezliği yer almaktaydı.

\section{TARTIŞMA}

Tüm canlı doğumlarda DKH insidansı \%0.8-0.9 arasındadır (8). Solunum sıkıntısı, siyanoz ve şok tablosu gibi ağır belirtiler eşlik edebileceği gibi hastada tek başına üfürüm de görülebilir (9). Kritik DKH vakalarının erken tanısı kalp yetmezliği, kardiyovasküler kollaps ve ani ölümün engellenmesi açısından önemlidir (10). Yenidoğanın kardiyovasküler sistem hastalıklarının tanınması için ekokardiyografi kullanımı giderek artmaktadır ve altın standart haline gelmiştir (11).

Literatürdeyapılan çalışmalardaDKH sıklığı \%1.6, \%4.9ve \%11.7 ile değişen oranlarda bildirilmiştir (12-14). Bu oran çalışmamızda \%13.2 olarak bulundu. Merkezlerin yoğunluğuna göre oranlar farklılık gösterebilir. Tüm yenidoğanlar ile kıyaslandığında, hastaneye yatan bebeklerin hasta olmaları, her gün detaylı muayene edilmeleri, daha sık ekokardiyografik değerlendirme yapılması, YD nabız oksimetre taramasının önem kazanması nedeniyle bu grupta DKH sıklığının daha yüksek çıkması beklenen bir sonuçtur. Bunun yanında Ülkemizde DKH'nın tanı ve tedavisi ile ilgili deneyimler ve olanaklar son yıllarda hızı bir şekilde artmaktadır.

Yalaki ve ark. (4) çalışmasında 631 bebeğin 196'sının (\%31.1) preterm, 339'u (\%53.7) erkek, bebeklerin doğum ağılığı ortalaması 3023 \pm 698 gr olarak bildirilmiştir. Varal ve ark. (15) yapmış olduğu bir çalışmada benzer sonuçlar kaydedilmiştir. Bu çalışmada 365 bebeğin 220'si (\%60.3) term, \%65'i erkek 
Tablo VI: Genetik Sendrom Eșlik Eden Hastaların Değerlendirilmesi

\begin{tabular}{|c|c|c|c|c|}
\hline Sayı & Genetik Sendrom & Cinsiyet/Sayı & Majör EKO bulgusu & Ek kardiyak patoloji \\
\hline 10 & Down S & $\mathrm{E} / 5, \mathrm{~K} / 5$ & ASD (5), VSD (3), PDA (2) & Interatriyal Anevrizma (1), AY (1), PHT (1) \\
\hline 2 & Edward S. & $\mathrm{K} / 2$ & VSD + PDA (2) & PHT (1), Biküspit Aorta (1) \\
\hline 1 & Di George S. & $E$ & $\mathrm{PA}$ & Tek Av Kapak, ÇSVK, MAPKA \\
\hline 1 & Noonan S. & K & ASD & - \\
\hline 1 & TAR S. & K & VSD & - \\
\hline 1 & Kasabach Merritt S. & E & ASD & KMP \\
\hline 1 & Poland S. & E & $\mathrm{PD}$ & - \\
\hline 1 & Cri Du Cat S. & E & $\mathrm{VSD}+\mathrm{PDA}$ & - \\
\hline 1 & 46xxt (6;21(Q12;10)) & K & AK & ASD, VSD, PDA \\
\hline 1 & Mozaik Pallister Killian S. & K & ASD & Biküspit Aorta \\
\hline 1 & Finn Tipi Nefrotik S. & K & $\mathrm{PD}$ & - \\
\hline 1 & SERAC 1 Homozigot & E & ASD & Septal Hipertrofi \\
\hline 1 & Pridoksin Eksikliği & E & ASD & - \\
\hline 1 & SMA-1 & E & $\mathrm{PD}$ & Septal Hipertrofi \\
\hline 1 & Q318X & K & $\mathrm{PD}$ & - \\
\hline 1 & PK285N - Homozigot & K & $\mathrm{ASD}+\mathrm{PDA}$ & - \\
\hline
\end{tabular}

AK: Aort Koarktasyonu, AY: Aort yetmezliği, ÇSVK: Çift süperior vena kava, EKO: Ekokardiyografi, KMP: Kardiyomyopati, ASD: Atriyal septal defekt, VSD: Ventiküler septal defekt, PDA: Patent duktus arteriozus, PD: Pulmoner darlik, PA: Pulmoner atrezi, PHT: Pulmoner hipertansiyon, MAPKA: Majör aortopulmoner kollateral arter, PD: Pulmoner darlik

ve ortalama doğum ağırlığı 2696 \pm 826 gr olarak saptandı. Çalışmamızda prematür hasta oranı mevcut literatüre göre daha fazla olması nedeniyle ortalama doğum haftası ve doğum ağırlığı diğer çalışmalardan daha düşük saptanması beklenen bir durumdur. Bu çalsşmada da literatürle uyumlu olarak tüm doğumsal kalp defektleri, önemli ve ciddi kalp defektleri, özellikle siyanotik ve kompleks olanları erkeklerde kızlardan daha fazla saptanmıştır (16).

Doğumsal kalp hastalığı olan bebekler özellikle yaşamın ilk günlerinde farklı nedenler ilede hastaneye yatırlırlar $(4,13)$. Çalışmamızda hastaların en sık kalp dışı nedenlerle hastaneye yattığı, bu nedenlerin de en sık solunumsal hastalıklar (\%28.3) olduğu görüldü. Diğer en sık nedenler ise enfeksiyöz hastalıklar, sarılık ve GiS hastalıkları kaynaklıydı. Bulut ve ark. (14) ile Yalaki ve ark. (4) yaptığı çalışmalarda da benzer sonuçlar bildirmişlerdir.

Çalışmamızda yatış süreleri incelendiğinde en uzun ortalama yatış süresi sıklık sırasına göre prematürite, GiS hastalıkları, metabolik hastalıklar ve genetik hastalıklar nedeni ile olduğu görülmüştür (Tablo II). Kardiyak nedenler ise 5. sırada yer almaktadır. Çalışmamızda başvuru ve yatışın kalp dışı nedenlerle daha yüksek bulunması, hastanemizde kadın hastalıklarıdoğum kliniğinin bulunmaması ve buna bağlı prenatal DKH tanısı alan hasta ve annelerinin takibinin yapılmaması, kalpdamar cerrahisi kliniği olmadığı için cerrahi gerektiren kardiyak patolojilerine sahip hastaların merkezimize yönlendirilmemesi, hasta popülasyonunun daha çok solunum sıkıntısı, sarılık, prematürite, metabolik-genetik bozukluk olan hastalardan oluşmasına bağlanabilir.
Ünitemizde izlenen bebeklerde en sık kardiyoloji konsültasyonu istenme nedeni üfürümdü ve bu bebeklerde DKH sıklığı \%63.5 olarak belirlendi.

Yenidoğanda üfürüm $\mathrm{DKH}$ açısından önemli bir bulgudur $(9,14)$. Ünitemizde izlenen yenidoğanlardan en sık kardiyoloji konsültasyonu istenme nedeni \%27.4 ile üfürümdü. Bulut ve ark. (14) yine isebu oran \%39.3 olarak kaydedilmiștir. Şap ve ark. (17) çalışmalarında patolojik üfürüm olduğu düşünülen 147 bebekten sadece 12'sinde normal EKO bulguları saptamış, üfürümü olmayan veya masum üfürüm duyulan 273 hastanın 114'ünde ise (\%42) DKH tespit etmişlerdir. Bu nedenlerle üfürüm duyulması $\mathrm{DKH}$ düşündürse bile, üfürüm duyulmadan da diğer fizik muayene bulgularıyla birlikte şüphe edildiğinde EKO yapılmasını önermiş̧lerdir.

Literatürde en sık görülen doğumsal kalp hastalığı VSD'dir ve sıklığı \%25-30 arasında değişmektedir (6). Çalışmamızda toplam 70 hastada VSD (\%19.2) görülmüştür.Yenidoğan döneminde ikinci en sık DKH olarak ASD (\%8-9) görülmektedir (18). Şimşek ve ark. (12) yaptığı bir çalışmada en sık görülen asiyanotik DKH sırası ile VSD (\%31.3), ASD (\%30.1), PDA (\%21.6) saptanmıştır. Görülme sıklığındaki bu değişiklik kullanılan tanı yöntemlerine, vakaların seçilme yöntemine ve yaşlarına bağlı değişiklik gösterebilir. Çalışmamızda asiyanotik DKH içinde sıklık sırasına göre izole ASD (\%40.8), izole PD (\%15.3), izole PDA (\%13.4), izole VSD (\%9.3) saptandı.Şahin ve ark. (19) çalışmamıza benzer sonuçlar rapor etmişlerdir.

Çalışmamızda siyanotik DKH sıkığı \%3.8 ( $n=14)$ olmakla birlikte bunlar içinde ilk sırada hipoplastik sol kalp sendromu (\%1.1) yer almaktaydı. Ekici ve ark. (20)'nın çalışmasında siyanotik DKH 
Tablo VII: Ekstrakardiyak Anomalilerin Sistemlere Göre Dağılımı* .

\begin{tabular}{ll}
\hline \multicolumn{1}{c}{ Sistem } & $\mathbf{n}(\%)$ \\
\hline Gastrointestinal sistem & $15(25.9)$ \\
Özofagus atrezisi & $8(13.8)$ \\
Duedonal atrezi & $3(5.2)$ \\
Omfolosel & $1(1.7)$ \\
Anal atrezi & $2(3.4)$ \\
İmperfore anüs & $1(1.7)$ \\
Kas-iskelet sistemi & $9(15.5)$ \\
Ekstremite anomalisi & $9(15.5)$ \\
Solunum sistemi & $9(15.5)$ \\
Trakeoözofagial fistül & $6(10.3)$ \\
Koanal atrezi & $3(5.2)$ \\
Kraniofasyal anomali & $9(15.5)$ \\
Yarık damak-dudak & $9(15.5)$ \\
Genitoüriner sistem & $8(13.8)$ \\
Ambigius genitale & $3(5.2)$ \\
Hipospadias & $1(1.7)$ \\
Hidroüreteronefroz & $1(1.7)$ \\
Renal agenezi & $3(5.2)$ \\
Santral Sinir sistemi & $8(13.8)$ \\
Hidrosefali & $5(8.6)$ \\
Meningomyelosel & $3(5.2)$ \\
Diğer & $36(9.9 \dagger)$ \\
Dismorfik yüz & \\
\hline
\end{tabular}

*: 1 hastada birden fazla majör ekstrakardiyak anomali bulunabilir.t: 365 adet hastada yüzde

sıklğı \%27.5; bunların içinde en sık \%4.2 BAT bulunmuştur. Şimşek ve ark. (12) yaptığı çalıșmada bu oran \%9.4 saptanmış olup, tanı sıklı̆ı sırasıyla FT, BAT ve HSKS olarak rapor edilmiștir. Çalışmamızda siyanotik DKH oranının daha düşük bulunmasının nedeni; katater anjiografi laboratuvarı, kadın hastalıklarıdoğum kliniği ve kalp-damar cerrahisi kliniğinin hastanemizde bulunmamasına, bu yüzden siyanoz saptanan, kritik DKH'den şüphelenilen ve girişimsel işlem gereken hastaların merkezimize yönlendirilmemesine bağlanabilir. Hastanemizde, yine bu birimler olmadığı için, prenatal dönemde DKH tanısı alan bebek ve annenin takibi, sevki ve yatışı yoktur. Bunun sonucu olarak yenidoğan ünitemizdeki asiyanotik DKH oranının yüksek olması (\%96.2) beklenen bir durumdur. Nitekim çalışmamızda siyanoz nedeniyle kardiyoloji konsültasyonu istenme nedeni \%6.6 olup oldukça düşüktür. Buna karşın diğer çalışmalarda siyanozun pediatrik kardiyoloji konsültasyonu istenmede önemli bir neden olduğu görülmüştür $(12,14,21)$.

Doğumsal kalp hastalığı olan olgularının \%2-4'ü bilinen çevresel ya da maternal nedenlerle ilişkilidir. Maternal diyabetes mellitus, fenilketonüri, sistemik lupus eritematosus ve maternal ilaç alımı ve anne baba arasında akrabalık bulunması bilinen nedenlerdendir $(16,22)$. Bulut ve ark. (14) yaptığı bir çalışmada hastaların \%21.9'unda maternal ilaç kullanımı mevcuttu. Tanı alan hastaların annelerinde sistemik hastalık olarak en sık diyabet (\%5.7) bulunmaktaydı.Diyabetik anne bebeklerinde daha sık asimetrik septal hipertrofi ile seyreden hipertrofik kardiyomiyopati ve VSD, ASD, PD gibi DKH'da görülmektedir $(23,24)$. Karagöl ve ark. (25) yapmış olduğu 88 DAB'nden oluşan bir çalışmada \%32.5 septal hipertrofi bildirmişlerdir. Güven ve ark. (13) yaptıkları çalışmada DKH'li bebeklerin \%15'inde anne-baba arasında akrabalık tespit edilmiş olup, bunun çoğunluğunun birinci dereceden olduğu saptanmıştır. Bizim çalışmada DKH olan bebeklerde ebeveyn akrabalık oranı \%19.9 olup bunların \%70'ini 2. derece akrabalık olduğu, annelerin \%20.8'inde gebelikte teratojen olan ya da olmayan ilaç kullanımı ve \%9.3'ünün DAB öyküsü mevcuttu. Bununla birlikte bu çalsşmada DAB'nin \%32.4'ünde ASD, \%23.5'inde VSD, \%17.6'sında PD ve \%20.6'sinda septal hipertrofi kaydedildi.

Doğumsal kalp hastalığı ile ilişkisi en iyi bilinen ve en sık görülen kromozomal anomali Trizomi 21' dir $(14,26,27)$. Reinhold ve ark. (28) yaptığı $814 \mathrm{DKH}$ olgusunu içeren bir çalışmada hastaların \%5.6'sında genetik sendrom saptarken, en sık olanı \%1.4 ile Down Sendromu'ydu. Bu çalışmada benzer oranlar saptanmış olup \%7.1'inde genetik serdrom ve \%2.7'inde Down Sendromu bulundu (Tablo VI). Down Sendromlu olgulardaki kardiyak defektlerin yaklaşık yarısı AV kanal defektidir. Kalan patolojilerin çoğunu ise VSD, ASD ve PDA oluşturmaktadır (14). Aydoğdu ve ark. (29) çalışmasında ise \%42.9 ile VSD ilk sırada yer almakta olup, \%37.5 ile ASD ikinci sırada yer almaktadır. Çalışmamızda ise Down Sendromlu hastaların \%50'unda ASD, \%30'sinde ASD ve \%20'sinde PDA kaydedildi.

Doğumsal kalp hastalıkları olan çocukların yaklaşık \%26.5'inde ekstrakardiyak malformasyonlar görülmekte, bu da komorbidite ve mortalite riskini daha da artırmaktadır (30). Bosi ve ark. (31) $2442 \mathrm{DKH}$ olgusunun ekstrakardiyak malformasyon sıklığını \%25.8 olarak bildirirken, en sık etkilenen sistemi GiS saptamışlardır. Çalışmamızda olguların \%10.1'inde $(n=37)$ bir veya daha fazla majör ekstrakardiyak anomali saptanırken, literatüre benzer şekilde \%25.9'unu Gis anomalileri oluşturmaktaydı.

Telekardiyografi kalbin yeri ve boyutu, kardiyomegali varlığı ve pulmoner kan akımı hakkında bilgi verir (32). Kamaşak ve ark. (33) yaptığı bir çalısmada 308 üfürümü olan olgular incelenmiş, kardiyak patolojisi olan 49 hastanın 15'inde KTO yüksek ve bunların da sadece 3'ünde DKH tespit edilmiştir. Aynı çalışmada TELE'nin DKH tanısında tek başına yeterli olmadığını belirtmişlerdir. Yenidoğan ünitemizde KTO hesaplanabilen bebeklerde siyanotik DKH olan grupta KTO anlamlı yüksek bulundu $(p<0.05)$. Nitekim KTO'nun normalden fazla ise DKH açısından anlamlı bir bulgu iken KTO oranı normal olan DKH tanısında tek başına yeterli olmadığı unutulmamalıdır. Pediatrik kardiyoloji ya da EKO imkanı olmayan merkezlerde fizik muayene ve vital bulgulara ek olarak TELE yardımcı araç olarak kullanılabilir.

Son yıllarda DKH'ye erken tanı konulabilmesi için, nabız oksimetre taraması yapılması önerilmektedir (34). Amerikan Pediatri Akademisi'nin önerisine göre, sağ üst ekstremite ve alt ekstremite saturasyonlarından herhangi biri \%90'ın altında ise ekokardiyografik olarak siyanotik DKH'nin dışlanması gerekmektedir (35). Çalışmamızda hastaların oksijen saturasyon ölçüm ortalaması \%94.65 \pm 7.86 olarak saptanırken, bu ölçüm 
siyanotik DKH anlamlı düşük bulundu ( $\mathrm{p}<0.05)$. Arlettaz ve ark. (36) çalışmasında 3262 YD'nin doğumdan sonra 6 ile 12 saat arasında postduktal saturasyon ölçümü yapılmıştır. Illk ölçümde saturasyonu <\%90 saptanan 21 ; kontrol ölçümünde saturasyonu <\%95 ölçülen 3 hastaya EKO yapılmış, 17 tanesinde DKH saptanmış olup bunların da 15'inde siyanotik DKH olduğu rapor edilmiştir. Saturasyonu >\%94 olan 23 hastada ise sonradan çeşitli nedenlerle EKO yapılmış olup hepsinde asiyanotik DKH saptandığı görüldü. Çalışmamızda tek zamanlı nabız oksimetre ölçümleri yapılmış olup asiyanotik DKH olan grupta SatO2 >\% 94 olanların ve siyanotik DKH grupta ise SatO2 <\%90 olanların çoğunlukta olduğu kaydedildi $(p<0.05)$. Asiyanotik $\mathrm{DKH}$ grubundaki hastaların nabız oksimetre ölçümü $<\% 90$ olanlarda en sık yatış sebebini \%66.7 ( $n=24)$ ile solunumsal hastallılar olușturduğu görüldü $(p<0.05)$. Bulgularımız nabız oksimetrik taramanın asemptomatik yenidoğanlarda siyanotik DKH'yi saptamak için etkili, doğru ve güvenilir bir yol olduğunu,hastaların saturasyon ölçümleri kalıcı olarak <95 \%'in altındaysa ve/veya klinik belirtiler eșlik ediyorsa DKH yönünden pediatrik kardiyoloji tarafindan değerlendirilmesini desteklemektedir.

Doğumsal kalp hastalıklı olgularda mortalite oranları merkezlere göre değişmektedir. En sık ölüm nedenleri içinde kalp yetmezliği, sepsis ve pnömoni yer almaktadır (14, 21). Benzer șekilde çalışmamızda da en sık ölüm nedenleri sırasıyla sepsis (\%72), kardiyak nedenler (\%20), dissemine intravasküler koagulasyon (\%4) ve metabolik kriz (\%4) olarak kaydedildi. Ölüm oranlarını Karabıyık ve ark. (37) çalışmasında \%4.2 ve Tokel ve ark. (38) çalışmasında ise \%23.6 rapor etmişlerdir. Mortalite oranlarının Tokel ve ark. (38) çalıșmasında yüksek olması ise merkezin başlıca girişimsel ve düzeltici operasyonların yapıldığı merkez olmasına, intra ve postoperatif komplikasyonların fazla görülmesine bağlı olabileceğini belirtmișlerdir. Karabıyık ve ark. (37) çalışmasında ölüm oranın düşük saptanması, çalışmanın tarama çalıșması olması ve DKH sıklı̆ı̆ını düşük olmasından kaynaklanabilir. Çalışmamızda ise ölüm oranı \%6.8 saptanmış olup, bu olguların ölüm nedeni tek başına kardiyak patolojilere bağlı olmayıp, eșlik eden prematürite, kromozomal veya ekstrakardiyak anomaliler ve çoğu kez ventilatör tedavisine bağı komplikasyonların da bu oranı artırdığı düşünülmüştür.

\section{SONUÇ}

Çalışmamızda yaklaşık döıt yıllık dönemde yenidoğan kliniğimize yatıılarak izlenen hastalar arasında DKH sıklığı \%13.2 olup bu hastaların önemli bir kısmında asiyanotik kalp hastalıkları saptandı. Hastaların en sık kalp dışı nedenlerle hastaneye başvurduğu, bunlar içinde de sıklıkla solunum sıkıntısı olduğu; en sık kardiyoloji konsültasyonu nedeni ise \%27.4 ile üfürüm duyulması, bunu sırasıyla solunum sıkıntısı (\%15.9), prematürite (\%10.1), metabolik hastalık (\%9.9) takip ettiği görüldü. Hastaların \%96.7 ( $n=353$ )'sinde yenidoğan döneminde bulgu görüldüğü için DKH'den şüphelenilerek ekokardiyografi yapılmışıı.
Yenidoğan bebek ölümlerinin en önemli nedenleri arasında DKH önemini korumaktadır. Yenidoğanlarda en önemli klinik DKH bulgusu patolojik üfürüm duyulmasıdır. Bunun yanında kalp dışı nedenlerle yatıılan yenidoğanlarda da DKH olabileceği, dikkatli fizik muayene ve izlem yapılması gerektiği, erken tanı ve tedavinin DKH için önemli olduğu unutulmamalıdır. Prematüre bebekler, kromozomal veya ekstrakardiyak anomalileri saptanan olgular ve DAB'lerde sıklikla eșlik eden kardiyovasküler sorunlarla karşılaşılmaktadır. Bu hastalarda morbidite ve mortalite riski taşıdığından rutin ekokardiyografik değerlendirmenin yararlı olacağı düşünülmektedir.

\section{KAYNAKLAR}

1. Bernstein D. Congenital heart disease. In: Behrman RE, Kliegman $\mathrm{RM}$, Jenson HB, editors. Nelson textbook of pediatrics. 18th ed. Philadelphia: Saunders; 2007:1878-942.

2. van der Linde D, Konings EE, Slager MA, Witsenburg M, Helbing WA, Takkenberg JJ, et al. Birth prevalence of congenital heart disease worldwide: a systematic review and meta-analysis. J Am Coll Cardiol 2011;58:2241-7.

3. Kliegman RM. In: Kliegman RM, Stanton B, St. Geme J, Schor N, editors. Nelson Textbook Of Pediatrics. 20th ed. Philadelphia: Elsevier 2016;2182-7.

4. Yalaki Z, Çiftçi N, Kara S, Arıkan Fi, Dallar YB. Yenidoğan Yoğun Bakım Ünitesinde İzlenen Bebeklerde Saptanan Konjenital Kalp Hastalıklarının Retrospektif Değerlendirilmesi. Türkiye Çocuk Hast Derg 2017;3:179-82.

5. Hoffman JI, Kaplan S. The incidence of congenital heart disease. J Am Coll Cardiol 2002;39:1890-900.

6. Ertürk E, Kucukoduk S, Baysal K, Ayyıldız P, Yılmaz A, Oğu G. A Retrospective Evaluation of the Patients with Congenital Heart Disease in Neonatal Intensive Care Unit. J Curr Pediatr 2016;14:6773.

7. Lawn JE, Cousens S, Zupan J. 4 million neonatal deaths: when? Where? Why? Lancet London, England 2005;365:891-900.

8. Bernier PL, Stefanescu A, Samoukovic G, Tchervenkov Cl. The challenge of congenital heart disease worldwide: epidemiologic and demographic facts. Seminars Thorac Cardiovascular Surg Pediatric Card Surg Annu 2010;13:26-34.

9. Ainsworth S, Wyllie JP, Wren C. Prevalence and clinical significance of cardiac murmurs in neonates. Arch Dis Child Fetal Neonatal Ed 1999;80: 43-5.

10. Altun D. Postoperatif Yenidoğan Kardiyak Yoğun Bakım Prensipleri. ACU Sağlık Bil Derg 2018;9:38-44.

11. Mertens L, Friedberg MK. The gold standard for noninvasive imaging in congenital heart disease: echocardiography. Curr Opin Cardiol 2009;24:119-24.

12. Șimșek A, Baysal B. Yenidoğan Yoğun Bakım Ünitesi'nde Doğumsal Kalp Hastalığı Sıklık ve Dağılımı: Tek Merkez Deneyimi. Ortadogu Tip Derg 2019;11:446-9.

13. Güven H, Bakiler RA, Kozan M, Aydınlığlu H, Helvacı M, Dorak C. Yenidoğan servislerinde konjenital kalp hastalıkları. Çocuk Sağlığı ve Hastalıkları Dergisi 2006;49:8-11.

14. Bulut G, Ballı Ş, Atlıhan F, Meșe T, Çalkavur Ş, Olukman Ö. Yenidoğan servisinde izlenen doğumsal kalp hastalığı olanların retrospektif değerlendirilmesi. İzmir Dr Behçet Uz Çocuk Hast Dergisi 2012;2:141-7. 
15. Varal IG, Köksal N, Özkan H. Yenidoğan Yoğun Bakım Ünitemizde İzlenen Konjenital Kalp Hastalıkları: Sıklığı, Risk Faktörleri ve Prognoz. J Curr Pediatr 2015;13:159-64.

16. Gül Ö, Gürses D, Doğan M. Down sendromlu çocukların klinik ve ekokardiyografik değerlendirilmesi. Türkiye Çocuk Hast Derg 2017; 11:116-9.

17. Şap F, Baysal T, Karataş Z, Altın H, Alp H, Karaarslan S. Yenidoğan döneminde duyulan üfürümün doğuştan kalp hastalığın saptamadaki önemi. Yeni Tıp Dergisi 2012;29:80-3.

18. Porter JC, Feldt RH, Edwards WD, Seward JB, Schaff HV. Atrial septal defects. In: Allen HD, Gutgesell HP, Clark EB, Driscoll DJ, editors. Moss \& Adams Heart Disease in Infants, Children, and Adolescent including the Fetus and Young Adult 6th ed. Philadelphia: Lippincott Williams and Wilkins 2001;603-16.

19. Aydın Şahin D. Çocuk kardiyoloji polikliniğine başvuran yenidoğanlarda doğumsal kalp hastalığının değerlendirilmesi. Ortadoğu Tıp Dergisi 2018;10:365-60.

20. Ekici F, Ünal S, Dablan S, Alpan N, Şaylan Çevik B,Vidinlisan S. Yenidoğan yoğun bakım ünitesindeki 119 bebeğin klinik ve ekokardiyografik değerlendirilmesi. Türkiye Çocuk Hast Derg 2010;4:22-9.

21. Zan S, Yapıcıoğlu H, Erdem S, Özlü F, Satar M, Özbarlas N, ve ark. Çukurova Üniversitesi Tıp Fakültesi Hastanesi Yenidoğan Yoğun Bakım Ünitelerinde son beș yılda izlenen konjenital kalp hastalarının retrospektif incelenmesi. Çocuk Sağlığı ve Hastalıkları Dergisi 2015;58:7-16.

22. Bernstein D. Congenital heart disease. In: Behrman RE, Kliegman RM, Jenson HB, editors. Nelson textbook of pediatrics. 17th ed. USA: Saunders 2004;1499-554.

23. Saenz RB, Beebe DK, Triplett LC. Caring for infants with congenital heart disease and their families. American family physician 1999;59:1857-68.

24. Edwards WD. Classification and terminology of cardiovascular anomalies. In: Allen HD, Gutgessell HP, Clark EB, Driscoll DJ, editors. Moss \&Adams Heart Disease in Infants, Children, and Adolescents,including the Fetus and Young Adult. 6th ed. Philadelphia: Lippincott, Williams and Wilkins 2001;118-37.

25. Saygılı Karagöl B. Yenidoğan Yoğun Bakımında Yedi Yıllık Diyabetik Anne Bebeği Deneyimi. Çocuk Dergisi 2012;12:169-76.

26. Cantez T. Doğumsal kalp hastalıkları. In: Dadaloğlu T, editor. Neonataloji. Ankara: Nobel Tıp Kitabevleri 2000;391-4.
27. Șen ȘR, Aksu H. Aydın II Merkezindeki 15-49 Yaș Grubu Kadınlarda Akraba Evliliği Sıklığı ve Etkileyen Faktörler. FN Hem Derg 2015;23:126-35.

28. Reinhold-Richter L, Fischer A, Schneider-Obermeyer J. Congenital heart defects. Frequency at autopsy. Zentralbl Allg Pathol 1987;133:253-61.

29. Aydoğdu SA, Münevver Türkmen M, Özkan P. Adnan Menderes Ünıversitesi Yenidoğan yoğun bakım ünıtesinde izlenen bebeklerde doğumsal kalp hastalığı sıklığı. ADÜ Tıp Fakültesi Dergisi 2008;9:58.

30. Gonzalez JH, Shirali GS, Atz AM, Taylor SN, Forbus GA, Zyblewski $\mathrm{SC}$, et al. Universal screening for extracardiac abnormalities in neonates with congenital heart disease. Pediatric cardiology 2009;30:269-73.

31. Bosi G, Garani G, Scorrano M, Calzolari E. Temporal variability in birth prevalence of congenital heart defects as recorded by a general birth defects registry. J pediatr 2003;142:690-8.

32. Bernstein D. Laboratory Cardiac Evaluation. In: Kliegman Robert M SGJ, editor. Nelson Textbook of Pediatrics E-Book. 21th ed. Philadelphia: Elsevier 2020;8635-80.

33. Kamaşak T, Dilber E. Çocukluk Çağındaki Masum Üfürümlerin Tanısında Fizik Muayene, Elektrokardiyografi, Telekardiyografi ve Ekokardiyografinin Yeri. Online Türk Sağlık Bilimleri Dergisi 2019;43:360-76.

34. Frank LH, Bradshaw E, Beekman R, Mahle WT, Martin GR. Critical congenital heart disease screening using pulse oximetry. J Pediatr 2013;62:445-53.

35. Mahle WT, Newburger JW, Matherne GP, Smith FC, Hoke TR, Koppel R, et al. Role of pulse oximetry in examining newborns for congenital heart disease: a scientific statement from the AHA and AAP. Pediatrics 2009;124:823-36.

36. Arlettaz R, Bauschatz AS, Mönkhoff M, Essers B, Bauersfeld U. The contribution of pulse oximetry to the early detection of congenital heart disease in newborns. Eur J Pediatr 2006;165:94-8.

37. Karabıyık N, Kavuncuoglu S, Besikçi R. Yasamın ilk haftasında konjenital kalp hastalıgı sıklığı. Çocuk Dergisi 2003;3:114-8.

38. Tokel K SA, Mercan S, Varan B, Gürakan B, Așlamacı S. Doğumsal kalp hastalıklı yenidoğanların değerlendirilmesi. Türk Pediatri Arşivi 2001;36:138-43. 